\title{
A Fast Ultrasound-assisted Extraction Sample Preparation for Multi-elemental Determination of Contaminants in Pharmaceutical Ingredients by ICP-MS
}

\author{
Giovanna de Fatima Moreno Aguiara ${ }^{a}$, Bruno Lemos Batista ${ }^{a, b}$, Eloísa Silva de Paula ${ }^{a}$, \\ Andres Dobal Campígliac ${ }^{c}$, and Fernando Barbosa, $\mathbf{J r}^{\text {a }}$ \\ ${ }^{a}$ Laboratório de Toxicologia e Essencialidade de Metais, Depto. de Análises Clínicas, \\ Toxicológicas e Bromatológicas, Faculdade de Ciências Farmacêuticas de Ribeirão Preto-USP, \\ Avenida do Café s/n, Monte Alegre, 14040-903, Ribeirão Preto-SP, Brazil \\ b Universidade Federal do ABC, Centro de Ciências Naturais e Humanas, \\ Rua Abolição s/n, Bangu, 09210-180, Santo André-SP, Brazil \\ c University of Central Florida, Orlando, FL, USA
}

\section{INTRODUCTION}

Ensuring the safety and efficacy of pharmaceutical products is essential. The safety of a drug is determined by its pharmacological and toxicological profile as well as the presence of impurities that can cause detrimental effects to human health. Ideally, the possibility of adverse impurities in the final product should be eliminated from the beginning of the manufacturing process, i.e., from the raw materials. It is under this perspective that the monitoring of drug impurities becomes extremely relevant for the quality control of pharmaceutical products.

Since the introduction of the International Conference on Harmonisation $(\mathrm{ICH})$ series of guidelines (1-4) to the current date, a significant change has occurred in the definition of quality of pharmaceuticals. The main focus of the ICH Guidelines has shifted from the definition of purity to impurities. According to the current guidelines, an impurity is a matrix component chemically different than the entity defined as the drug. According to their chemical nature and source of origin, drug impurities can be classified as organic, inorganic, and residual solvent impurities. The work presented here deals with the analytical monitoring of inorganic impurities.

*Corresponding author.

E-mail: fbarbosa@fcfrp.usp.br

Tel: 55-16-33154701

\section{ABSTRACT}

There is a great demand for the development of simple, highly sensitive and selective methods for elemental analysis of active pharmaceutical ingredients (API). According to the United States Pharmacopeia (USP), the presence of some elements in pharmaceutical ingredients should be monitored routinely. The present study addresses an important issue for the elemental analysis of active pharmaceutical ingredients (API), which is sample preparation. Ultrasoundassisted extraction (UAE) was evaluated for the purpose at hand with the aid of inductively coupled plasma mass spectrometry with quadrupole (q-ICP-MS) and dynamic reaction cell (DRCICP-MS). The limits of detection varied from $0.001 \mathrm{ng} \mathrm{g}^{-1}\left({ }^{103} \mathrm{Rh}\right)$ to $0.083 \mathrm{ng} \mathrm{g}^{-1}$ ( $\left.{ }^{75} \mathrm{As}\right)$. Validation of the proposed procedure was achieved by performing recovery experiments and by comparing the results obtained for the analysis of seven commercial products using the proposed procedure with those obtained by using microwave-assisted digestion (MAD). In addition, the determined values in commercial samples did not exceed the concentration limits for oral drug products (drug substances and excipients) established by the USP Chapter $<232>$.

In addition to raw materials, the presence of inorganic - or elemental - impurities in pharmaceutical for- mulations results from the use of reagents, ligands, and catalysts in their manufacturing process. The residual impurities are characteristic of the synthetic route and, therefore, well known and defined (1-5). Despite the tremendous advances of instrumental methods of analysis in the past decades, the monitoring protocols established in the international pharmacopeia (6-7) are based on wet chemical techniques. The large amount of sample ( $>1.0 \mathrm{~g}$ ) required due to the relatively poor limits of detection $\left(\mu \mathrm{g} \mathrm{g}^{-1}\right)$ increases the analysis cost for quality control purposes. The time-consuming procedures are unsuitable for routine analysis of the numerous samples. In addition, the numerous experimental steps increase the possibility of sample contamination and deteriorate the precision of measurements. The same is true for potential elemental loss and accuracy of analysis. The latter is also affected by the lack of specificity (6-8).

In 2013, the United States Pharmacopeia (USP) devoted two new chapters to elemental impurity procedures (9-10). The use of analytical techniques capable to provide more accurate and precise results than those obtained with wet chemical procedures was recommended for the determination of As, Cd, Cr, Cu, Hg, Ir, Mo, Ni, Os, $\mathrm{Pb}, \mathrm{Pd}, \mathrm{Pt}, \mathrm{Rh}, \mathrm{Ru}$, and $\mathrm{V}$. The methods of inductively coupled plasma optical emission spectrometry (ICP-OES) and inductively coupled plasma mass spectrometry 
(ICP-MS) were both suggested for the purpose at hand (9-11).

The present report deals with the analysis of active ingredients of pharmaceutical drugs via ICP-MS. In comparison to ICP-OES (11), ICPMS presents the advantage of simultaneous multi-elemental capability with enhanced sensitivity (12-14). ICP-MS offers wider linear dynamic ranges than ICP-OES, simpler spectral interpretation and isotopic information. Wide linear dynamic ranges make the determination of major and trace elements possible with a single sample injection (12-14).

The preparation of solid samples is still the "bottleneck" of atomic spectroscopic techniques. Cumbersome and time-consuming procedures, incomplete sample dissolution, precipitation of insoluble elements, sample contamination and elemental losses due to extreme sample heating are some of the disadvantages of dry ash methods and wet digestion procedures with open and closed vessels $(15,16)$. Ultrasound-assisted extraction (UAE) is an alternative sample preparation procedure that has emerged in the last years with promising potential for rapid and simple sample preparation of solid samples. This procedure is based on the leaching of metal ions from powdered materials in slurries containing an appropriate solvent, generally a diluted acid solution. UAE has been successfully applied for trace element determination by GFAAS or ICP-OES (17-19). However, only few applications of UAE are found in the literature using ICP-MS determination (20-21).

In this article, an ultrasoundassisted extraction procedure is proposed for the trace element determination in pharmaceutical ingredients by ICP-MS.

\section{EXPERIMENTAL}

\section{Instrumentation}

The measurements were performed with an ELAN ${ }^{\circledR}$ DRC $^{\mathrm{TM}}$ II ICP-MS (PerkinElmer, Inc., Shelton, CT, USA) operating either in the standard (q-ICP-MS) or dynamic reaction cell (DRC) mode. All measurements were made with the aid of a Pt sampler and skimmer cones. The instrumental conditions and measurement parameters are listed in Table I.

The determination of As, $\mathrm{Cr}$, and V was carried out under DRC conditions. All of the remaining elements were determined in standard mode. The reaction gas for the determination of $\mathrm{Cr}$ and $\mathrm{V}$ was ammonia. The reaction gas for the determination of As was the mixture of $\mathrm{Ar} / \mathrm{H}_{2}$

TABLE I

ICP-MS Operating Conditions for Q-ICP-MS and DRC-ICP-MS

\begin{tabular}{ll}
\hline Instrument & ELAN DRC II ICP-MS \\
Spray chamber & Cyclonic (quartz) \\
Nebulizer & Meinhard (quartz, Type A) \\
RF power & $1100 \mathrm{~W}$ \\
Ar nebulizer gas flow rate & 0.56 to $0.98 \mathrm{~L} / \mathrm{min}$ (optimized daily) \\
q-ICP-MS & (standard mode) \\
Scanning mode & Peak hopping \\
Replicate time & $1 \mathrm{sec}$ \\
Dwell time & $50 \mathrm{~ms}$ \\
Sweeps/reading & 40 \\
Integration time & $2000 \mathrm{~ms}$ \\
Replicates & 3 \\
Isotopes & ${ }^{75} \mathrm{As},{ }^{111} \mathrm{Cd},{ }^{52} \mathrm{Cr},{ }^{63} \mathrm{Cu},{ }^{98} \mathrm{Mo},{ }^{60} \mathrm{Ni},{ }^{208} \mathrm{~Pb}$, \\
& $106 \mathrm{Pd},{ }^{103} \mathrm{Rh}$, and ${ }^{51} \mathrm{~V}$ \\
Correction Equation & \\
Lead = $\left({ }^{04} \mathrm{~Pb}-\left[0.230074 \times{ }^{202} \mathrm{Hg}\right]\right)$ & $\left.+{ }^{206} \mathrm{~Pb}+{ }^{207} \mathrm{~Pb}+{ }^{208} \mathrm{~Pb}\right)$ \\
DRC-ICP-MS (DRC mode) & \\
Isotopes & ${ }^{75} \mathrm{As}$ \\
Reaction Gas & $\mathrm{H}_{2} / \mathrm{Ar} 5: 95$ \\
$\mathrm{H}_{2} /$ Ar flow rate & 0.1 to $1.4 \mathrm{~mL} / \mathrm{min}($ daily optimization) \\
RPq range & 0.40 to 0.90 \\
Isotopes & ${ }^{52} \mathrm{Cr},{ }^{51} \mathrm{~V}$ \\
Reaction Gas & $\mathrm{Ammonia}\left(\mathrm{NH}{ }_{3}\right)$ \\
NH ${ }_{3}$ flow rate & 0.1 to $1.4 \mathrm{~mL} / \mathrm{min}($ daily optimization) \\
RPq range & 0.40 to 0.90 \\
\hline & \\
&
\end{tabular}

$(95 / 5 \% \mathrm{v} / \mathrm{v})$. The reaction gas flows were optimized to the final values of $0.70(\mathrm{Cr}), 1.00(\mathrm{~V})$, and $0.85 \mathrm{~mL}$ $\min ^{-1}$ (As). With the rejection parameter $(\mathrm{RPa})$ fixed at 0.1 , the optimized conditions for the rejection parameter $\mathrm{q}(\mathrm{RPq})$ were: 0.7 for $\mathrm{Cr}$, 0.85 for $\mathrm{V}$, and 0.8 for As.

Ordinary pharmaceutical formulations were ground thoroughly with a model 6800 Freezer/mill SPEX CertiPrep ${ }^{\circledR}$ (Metuchen, NJ, USA). Particle size measurements were carried out by using a laser particle size analyzer Coulter model LS230 (Miami, FL, USA).

A USS-100 controller was used for the vibracell VC 100 ultrasonic processor with a titanium probe (Sonics \& Materials, Danbury, CT, USA). 


\section{Chemicals}

High purity deionized water (resistivity $18.2 \mathrm{M} \Omega \mathrm{cm}$ ) from a Milli-Q ${ }^{\circledR}$ water purification system (Millipore Corporation, Bedford, MA, USA) was used for preparation of the samples and solutions. With the exception of nitric acid (Sigma, St Louis, MO, USA), all other chemicals were of analytical reagent grade (Sigma, St Louis, MO, USA). Hydrochloric and nitric acid were purified before use according to the standard sub-boiling procedure with the aid of quartz sub-boiling stills (Kürner Analysentechnik, Germany). Hydrogen peroxide (Merck, Darmstadt, Germany), L-cysteine (Sigma, St Louis, MO, USA), and sodium chloride (Puratonic, Ward Hill, MA, USA) were used as received. Argon (Ar) 99.999\%, ammonia $99.999 \%$, and $\mathrm{H}_{2} / \mathrm{Ar} 5: 95 \%$ were purchased from White Martins (São Paulo, SP, Brazil).

\section{Preparation of Stock Solutions and Working Standards}

A class 100 laminar-flow hood installed in a class 10,000 clean room was used for solution preparation. All solutions were prepared and stored in high-density polyethylene bottles, previously cleaned according to the following procedure: (a) soaking in $15 \%(\mathrm{v} / \mathrm{v})$ nitric acid for 24 hours; (b) rinsing five times with Milli-Q water; and (c) drying at room temperature overnight.

Multi-element stock solutions (PerkinElmer, Inc., Shelton, CT, USA) with individual concentrations at the $10-\mathrm{mg} \mathrm{L}^{-1}$ level were used to prepare the working standard solutions for ICP-MS and DRCICP-MS measurements. Working standards (1-20 $\left.\mu \mathrm{g} \mathrm{L}^{-1}\right)$ were prepared daily by serial dilution with $5.0 \%(\mathrm{v} / \mathrm{v})$ nitric acid. Yttrium was used as the internal standard at the $10-\mu g \mathrm{~L}^{-1}$ concentration. The internal standard was added to the working solutions from a $1000-\mathrm{mg} \mathrm{L}^{-1}$ stock solution (PerkinElmer, Inc., Shelton, CT, USA).

\section{Samples of Pharmaceutical Ingredients}

The samples consisted of seven active ingredients. These included six antibiotics (cephalexin, doxycycline hyclate, norfloxacin, oxytetracycline, penicillin $G$ potassium. and trimethoprim) and one anthelmintics (praziquantel). These samples were chosen according to their chemical composition and solubility for evaluation of the proposed sample preparation method. Because they are organic molecules, all have a high content of organic matter, such as Penicillin G potassium. Doxycycline hyclate contains chlorine and cephalexin contains sulfur, elements that may cause interference with ICP-MS. Norfloxacin, oxytetracycline, and trimethoprim have aromatic rings that may be more resistant to the oxidizing action of acids, requiring different strategies for extraction, and praziquantel is very poorly soluble in aqueous medium. Initially these samples were analyzed by a validated methodology using microwave digestion. These results were compared to those obtained by the methodology proposed by ultrasound-assisted extraction. The two methodologies used are described below.

\section{Sample Preparation}

\section{Cryogenic Grinding of Samples}

The grinding of pharmaceutical ingredients was accomplished by using a cryogenic mill with a selfcontained liquid nitrogen bath. This equipment exploits the grinding by impact with magnetic bars. The cylindrical grinding vial consists of a polycarbonate center tube, a magnetic bar, and two end plugs of stainless steel. After a period of sample precooling in the sampling vial, which is immersed in liquid nitrogen, an alternating magnetic field is applied so that the magnetic

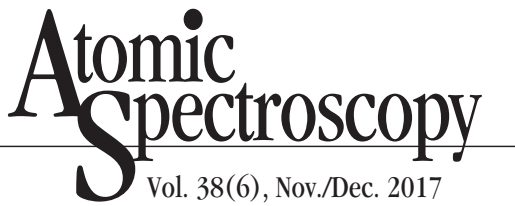

bar reaches the sample and end plugs of the tube at high speed with an average frequency of 20 impacts $\mathrm{s}^{-1}$. The precooling and grinding times were ranging from 5-20 minutes and 1-5 cycles of 2 minutes, respectively. After each grinding cycle, the magnetic field is turned off for 1 minute to allow sample re-cooling. A study of particle size distribution after grinding demonstrated that ordinary samples had a homogeneous distribution with $95 \%$ of the total volume composed of particles less than $40 \mu \mathrm{m}$ in diameter and with a mean particle size of $21 \mu \mathrm{m}$.

\section{Closed-vessel Microwave-assisted Digestion}

For microwave digestion, a previously proposed procedure (32) was adopted with some modifications. Briefly, $100 \mathrm{mg}$ of ground samples was mixed with $4 \mathrm{~mL}$ of nitric acid (65\% v/v) in a Perfluoroalkoxy alkane (PFA) digestion vessel. All digestion vessels were placed in an ETHOS Start D microwave oven (Milestone, USA). Digestion was carried out according to the heating program described in Table II. After cooling, the digestates were transferred to 50-mL conical tubes (Falcon ${ }^{\mathrm{TM}}, \mathrm{BD}$, USA) and brought to $25-\mathrm{mL}$ final volume with deionized water.

\section{Ultrasound-assisted Extraction}

For the ultrasonic extraction procedure, $30 \mathrm{mg}$ of each ground sam-

TABLE II

Heating Program of the Microwave Oven Used for Digestion of Active Pharmaceutical Ingredients Samples

\begin{tabular}{cccl}
\hline Step & $\begin{array}{c}\text { Time } \\
(\mathrm{min})\end{array}$ & $\begin{array}{c}\text { Power } \\
(\mathrm{W})\end{array}$ & $\begin{array}{c}\text { Temp. } \\
\left({ }^{\circ} \mathrm{C}\right)\end{array}$ \\
\hline 1 & 15 & 1100 & 120 \\
2 & 30 & 1100 & 170 \\
3 & 45 & 1100 & 160 \\
4 & 60 & 0 & cooling \\
\hline
\end{tabular}


ple was placed in a $15-\mathrm{mL}$ conical tube (Falcon ${ }^{\mathrm{TM}}, \mathrm{BD}, \mathrm{USA}$ ) and $2 \mathrm{~mL}$ of nitric acid $50 \%(\mathrm{v} / \mathrm{v})$ was added to the sample. The mixture was sonicated for 1 minute at $50 \mathrm{~W}$ (100\% amplitude). Ultrasound was generated with the aid of a titanium probe, a Vibracell VC 100 ultrasonic processor and a USS-100 controller (Sonics \& Materials, Danbury, CT, USA). The resulting slurry was centrifuged for $2 \mathrm{~min}$ utes at $900 \times \mathrm{g}$ and the supernatant was transferred to the $15-\mathrm{mL}$ Falcon conical tubes and brought to $10-\mathrm{mL}$ final volume with deionized water.

\section{Recovery Experiments}

Since to our knowledge there are no reference materials commercially available with similar composition to the samples analyzed, spike recovery experiments were carried out. For this experiment, five pharmaceutical ingredients of unknown composition were spiked with stock standards in concentrations ranging of $100 \%$ of the target limits stated by USP (23) and diluted to the working range of the calibrations curves. The selected drugs were doxycycline hyclate, cephalexin, norfloxacin, praziquantel, and trimethoprim. These samples were chosen according to their chemical composition and acidic solubility. All of them have a high carbon content. Some have elements that can cause interference, such as chlorine and sulfur in the doxycycline hyclate and cephalexin samples, respectively. Praziquantel is very poorly soluble in aqueous media, thus representing an analytical challenge to evaluate this parameter.

\section{RESULTS AND DISCUSSION}

\section{Optimization of DRC Operating Conditions for the ICP-MS Determination of As, $\mathrm{Cr}$, and $\mathrm{V}$}

Due to the high levels of concomitants in the pharmaceutical ingredient matrices such as chlo- ride, carbon, and others, the determination of As, Cr, and V by ICP-MS is affected by polyatomic interferences. These include - but are not restricted to - argon and chloride species, such as ${ }^{38} \mathrm{Ar}^{13} \mathrm{C}^{+},{ }^{35} \mathrm{Cl}^{16} \mathrm{O}^{+}$, ${ }^{40} \mathrm{Ar}^{35} \mathrm{Cl}^{+}$, and ${ }^{40} \mathrm{Ar}^{12} \mathrm{C}^{+}$. The analyses of ${ }^{51} \mathrm{~V}$ and ${ }^{75} \mathrm{As}$ are prone to the spectral interferences of ${ }^{38} \mathrm{Ar}^{13} \mathrm{C}^{+}$, ${ }^{35} \mathrm{Cl}^{16} \mathrm{O}^{+},{ }^{40} \mathrm{Ar}^{35} \mathrm{Cl}^{+}$, and ${ }^{40} \mathrm{Ar}^{35} \mathrm{C}^{+}$, respectively. The same is true for the presence of ${ }^{40} \mathrm{Ar}^{12} \mathrm{C}^{+}$, which is detected at the same nominal massto-charge ratio as the ${ }^{52} \mathrm{Cr}^{+}$isotope $(11,24,25)$. Under these conditions, the use of a Dynamic Reaction Cell ${ }^{\mathrm{TM}}$ (DRC ${ }^{\mathrm{TM}}$ ) in conjunction with ICP-MS instrumentation is essential to avoid any interference during the determination of As, Cr, and $\mathrm{V}$ in pharmaceutical active ingredients. DRCs are known to promote charge transfer or atom transfer reactions to minimize - or even remove - the presence of unwanted ions in the matrix of analysis. The formation of new interfering species is avoided by the tunable band-pass feature of the DRC that automatically sets a new mass transmission window of the DRC quadrupole (26-29).

The DRC settings were optimized with a synthetic mixture composed of $1.1 \mathrm{mg} . \mathrm{mL}^{-1}$ of L-cysteine and 0.5 mg. $\mathrm{mL}^{-1}$ of sodium chloride (which acted as sources of carbon, sulfur, sodium and chlorine) to provide the following precursors for polyatomic interferences: $0.33 \mathrm{mg} \cdot \mathrm{mL}^{-1}$ of carbon and $0.30 \mathrm{mg} \cdot \mathrm{mL}^{-1}$ of chlorine. Standard solutions of As, Cr, and $\mathrm{V}$ were added to this synthetic mixture at the concentration level of $1.0 \mu \mathrm{g} \mathrm{L}^{-1}$.

Figure 1 summarizes the results of the DRC optimization study. The lowest background equivalent concentration (BEC) values for the analysis of $\mathrm{Cr}$ and $\mathrm{V}$ were obtained under $\mathrm{NH}_{3}$ flow rates equivalent to 0.70 and $1.00 \mathrm{~mL} \cdot \mathrm{min}^{-1}$, respectively (see Figures 1a and 1c). The lowest BEC for the analysis of As was obtained with an $\mathrm{H}_{2} / \mathrm{Ar}$ flow rate equal to $0.85 \mathrm{~mL} \cdot \mathrm{min}^{-1}$ (see Figure 1e). Figures $1 \mathrm{~b}, 1 \mathrm{~d}$, and $1 \mathrm{f}$ show the signal-to-background ratios (S/B) as a function of RPq values under optimum reagent gas flow rates. All further determinations were then performed under best S/B conditions; i.e., RPq values equal to $0.70(\mathrm{Cr}), 0.85(\mathrm{~V})$, and 0.8 (As).

\section{Optimization of Ultrasonic Extraction Conditions}

The best conditions for the ultrasound-assisted extraction method (particle size and sample mass, time of extraction, and acid concentration) were optimized $(30,31)$. The optimization was carried out based on previous results of our group with ultrasound extraction of several elements in hair and food samples $(30,31)$. The experiments were carried out with a pool of several mixed and ground pharmaceutical ingredients. The pool, composed of doxycycline hyclate, cephalexin, norfloxacin, praziquantel, and trimethoprim, was homogenized, ground as described in the material and methods section, and previously analyzed by a reference method (with some modifications) where the samples were digested by using a microwave-assisted digestion system (32). Digestion was carried out according to the heating program described in Table II. The value obtained by the reference method was considered as $100 \%$ recovery (theoretical value), and was used for the calculation of analyte recoveries.

Particle size is an important parameter in order to obtain quantitative recoveries in the ultrasoundassisted extraction procedure. Larger particles sizes (>100 $\mu \mathrm{m})$ will require a higher sonication power for longer periods ( $>10$ minutes) to achieve quantitative recoveries, and are unsuitable for routine analysis of a large number of samples (33). On the other hand, 


\section{Atomic Spectroscopy \\ 1 Vol. 38(6), Nov./Dec. 2017}

some previous studies have demonstrated quantitative recoveries of several elements from biological samples after ultrasound extraction with sample sizes lower than $75 \mu \mathrm{m}$ (30-31, 33). A study of particle size distribution, after API cryogenic grinding, demonstrated that $95 \%$ of the total volume of particles in our samples had less than $40 \mu \mathrm{m}$ in diameter. Thus, in the present study it was decided to continue the experiments without any further attempts to decrease the sample particle size.

The optimization of extract concentration and sample mass was then carried out. Both nitric and hydrochloric acids were tested as extractants. Preliminary experiments were carried out with $50 \%$ (v/v) of each acid and maintaining the mass of pool sample in $25 \mathrm{mg}$, ultrasonic amplitude in $100 \%$, and sonication time in 10 minutes. Better recoveries, calculated by comparing the result obtained with the proposed methodology and the result obtained using the reference method (microwave digestion), were always observed in nitric acid medium. Then, further experiments testing the effect of the concentration of extractant were carried out with only nitric acid. The acid concentration was varied from $0 \%$ to
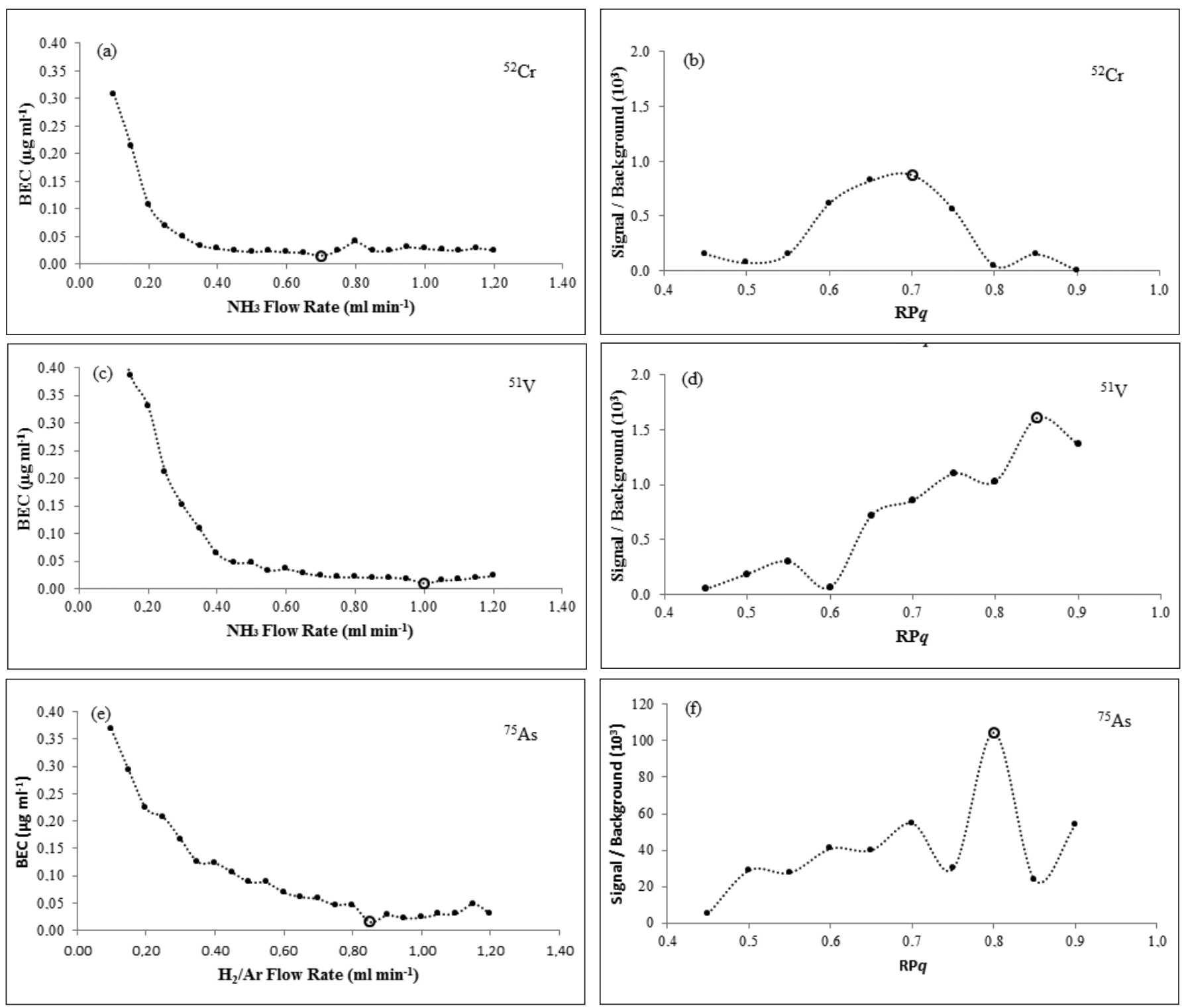

Fig. 1. DRC-ICP-MS optimization of $\mathrm{NH}_{3}$ flow rate for ${ }^{52} \mathrm{Cr}$ (a) and ${ }^{51} \mathrm{~V}$ (c) and $\mathrm{RPq}$ for ${ }^{52} \mathrm{Cr}$ (b) and ${ }^{51} \mathrm{~V}$ (d) and DRC optimization of $\mathrm{H}_{2} / \mathrm{Ar}$ flow rate for ${ }^{75} \mathrm{As}$ (e) and $\mathrm{RPq}$ for ${ }^{75} \mathrm{As}(f)$. 
$100 \%(\mathrm{v} / \mathrm{v})$. Nitric acid in 50\% (v/v) was efficient for quantitative recoveries of 9 analytes under study in the pool sample when the sample mass was fixed at $25 \mathrm{mg}$, ultrasonic amplitude at $100 \%$, and sonication time at 10 minutes. Quantitative recoveries were not acquired for Mo. The results are shown in Figure 2.

The amount of sample has a considerable influence on the extraction of the elements. Low amounts of sample may increase the influence of sample inhomogeneity and high amounts could lead to particle agglomeration, decreasing the ultrasonic action (34). Based on previous results of our group $(30,31)$, we evaluated the effects of sample mass by varying the amounts between 10 to $50 \mathrm{mg}$. For this experiment, nitric acid was maintained at $10 \%(\mathrm{v} / \mathrm{v})$, sonication time at 10 minutes, and ultrasonic amplitude at $100 \%$. Quantitative recoveries (84-101\%) and better precision $(<5 \%)$ for 9 analytes were observed with a sample mass of $30 \mathrm{mg}$. However, again the Mo recoveries were always lower than $80 \%$.

The time of extraction necessary for achieving total element extraction depends on analyte-matrix interaction, composition of the liquid media, and ultrasonic device used (35). Based on that, the sonication time was varied between 1 to 10 minutes, keeping ultrasound amplitude at $100 \%$ and extractant concentration $\left(50 \%, \mathrm{v} / \mathrm{v} \mathrm{HNO}_{3}\right)$, extractant volume $(2 \mathrm{~mL})$ and pool sample weight at $25 \mathrm{mg}$. Quantitative recoveries (82-106\%) were obtained for nine elements in this study with only 1 minute sonication time. Mo recoveries were always lower than $80 \%$. The results are shown in Figure 3.

\section{Analytical Figures of Merit (AFOM) of ICP-MS}

Table III summarizes the AFOM obtained with the instrumental method. Calibration curves were built with working solutions prepared in 5\% nitric acid solution (v/v). Correlation coefficients close to unity demonstrate excellent linear correlations in all cases. The limits of detection (LOD) were calculated as three times the standard deviation of 10 consecutive blank measurements. The limits of quantitation (LOQ) were measured in the same manner but calculated as 10 times the standard deviation of the

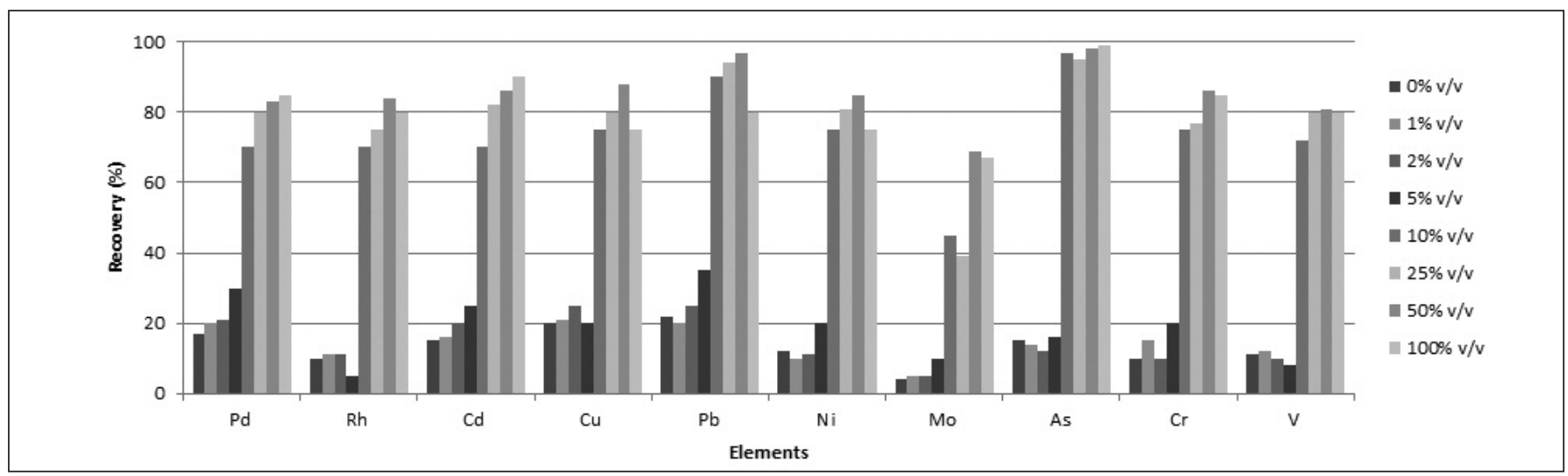

Fig. 2. Effect of the concentration of extractant. Acid concentration was varied from $0 \%$ to $100 \%$ v/v. See text for details.

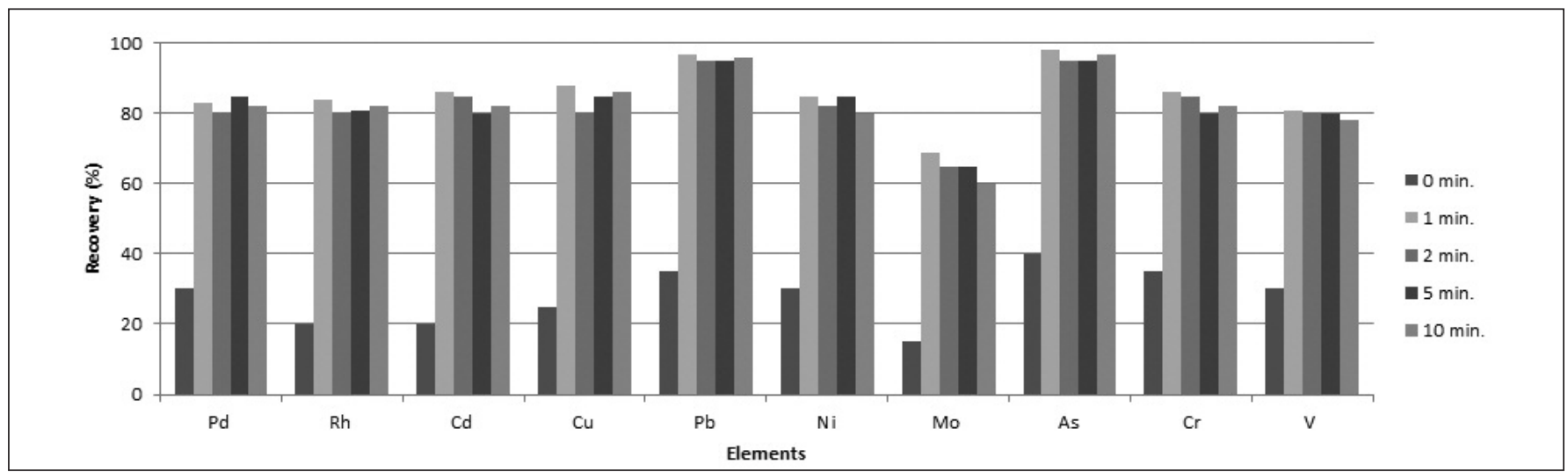

Fig.3. Extraction time optimization. Time was varied between 1 and 10 minutes. See text for details 
blank. Typical within-day $(n=6)$ and between-day $(n=12)$ precision of measurements provided relative standard deviations lower than 5 and $10 \%$, respectively.

\section{Validation of Analytical Method}

The commercial availability of standard reference materials for the validation of pharmaceutical methods of analysis is currently lacking. Recovery studies were made with five active ingredients spiked to concentrations of $100 \%$ of the target limit stated by USP (22) as described in recovery experiments. Table IV summarizes the obtained results. Good agreement of expected and experimental values was found in all the investigated matrices for nine targeted elements (Mo was the exception). Based on that, Mo was not considered in further experiments.

TABLE III

Limits of Detection (LOD), Limits of Quantification (LOQ), and Coefficient Correlation (r) Determined by ICP-MS

\begin{tabular}{cccc}
\hline Isotope & LOD $\left(\mathrm{ng} \mathrm{g}^{-1)}\right.$ & LOQ $\left(\mathrm{ng} \mathrm{g}^{-1}\right)$ & $\mathrm{r}$ \\
\hline${ }^{75} \mathrm{As}^{\mathrm{b}, \mathrm{c}}$ & 0.083 & 0.277 & 0.999815 \\
${ }^{111} \mathrm{Cd}^{\mathrm{a}}$ & 0.010 & 0.032 & 0.999981 \\
${ }^{52} \mathrm{Cr}^{\mathrm{b}, \mathrm{c}}$ & 0.020 & 0.067 & 0.999456 \\
${ }^{63} \mathrm{Cu}^{\mathrm{a}}$ & 0.038 & 0.127 & 0.999977 \\
${ }^{98} \mathrm{Mo}^{\mathrm{a}}$ & 0.004 & 0.013 & 0.999926 \\
${ }^{60} \mathrm{Ni}^{\mathrm{a}}$ & 0.038 & 0.126 & 0.999960 \\
${ }^{208} \mathrm{~Pb}^{\mathrm{a}}$ & 0.042 & 0.139 & 0.999988 \\
${ }^{106} \mathrm{Pd}^{\mathrm{a}}$ & 0.003 & 0.009 & 0.999936 \\
${ }^{103} \mathrm{Rha}^{51} \mathrm{~V}^{\mathrm{b}, \mathrm{c}}$ & 0.001 & 0.003 & 0.999903 \\
\hline
\end{tabular}

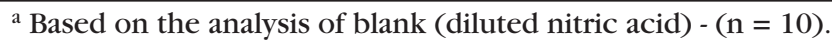

${ }^{b}$ Based on the analysis of blank (synthetic matrix solution) - ( $\mathrm{n}=10$.

${ }^{\mathrm{c}}$ Analysis with DRC-ICP-MS

TABLE IV

Recovery Experiments -

Each of the Evaluated Elements Added to Standard Solution in the Concentration of $10 \mathrm{~g} \mathrm{~L} \mathrm{~L}^{-1}$ (see text for details)

Cephalexin Doxycycline Norfloxacin Praziquantel Trimethoprim Recovery $(\%) \pm \mathrm{SD}^{*}$

\begin{tabular}{llllll}
\hline As** $^{* *}$ & $95 \pm 1.1$ & $101 \pm 3.6$ & $100 \pm 4.4$ & $92 \pm 2.0$ & $91 \pm 1.1$ \\
$\mathrm{Cd}$ & $92 \pm 2.7$ & $87 \pm 1.3$ & $91 \pm 3.2$ & $86 \pm 3.1$ & $89 \pm 1.3$ \\
$\mathrm{Cr}{ }^{* *}$ & $95 \pm 3.4$ & $88 \pm 3.8$ & $97 \pm 4.2$ & $89 \pm 2.5$ & $95 \pm 0.4$ \\
$\mathrm{Cu}$ & $93 \pm 3.1$ & $87 \pm 3.6$ & $91 \pm 2.6$ & $101 \pm 4.3$ & $101 \pm 3.2$ \\
$\mathrm{Mo}$ & $81 \pm 3.4$ & $70 \pm 3.8$ & $67 \pm 3.8$ & $84 \pm 3.7$ & $70 \pm 1.0$ \\
$\mathrm{Ni}$ & $91 \pm 2.7$ & $88 \pm 2.3$ & $88 \pm 2.7$ & $88 \pm 4.0$ & $91 \pm 3.2$ \\
$\mathrm{~Pb}$ & $99 \pm 1.8$ & $97 \pm 1.2$ & $96 \pm 4.0$ & $84 \pm 4.7$ & $100 \pm 3.1$ \\
$\mathrm{Pd}$ & $84 \pm 3.4$ & $90 \pm 4.3$ & $86 \pm 4.1$ & $95 \pm 3.6$ & $86 \pm 2.3$ \\
$\mathrm{Rh}$ & $87 \pm 4.2$ & $84 \pm 4.3$ & $94 \pm 3.1$ & $88 \pm 2.4$ & $88 \pm 2.2$ \\
$\mathrm{~V} * *$ & $87 \pm 3.1$ & $84 \pm 2.8$ & $88 \pm 3.8$ & $90 \pm 2.8$ & $87 \pm 0.4$ \\
\hline
\end{tabular}

* Results are presented as means \pm standard deviations (SD) obtained from three replicated analyses $(n=3)$

** As, Cr, and V were measured by DRC-ICP-MS

\section{Atomic Mpectroscopy \\ Vol. 38(6), Nov./Dec. 2017}

Determination of Elemental Impurities in Ordinary Pharmaceutical Ingredients via UAE-ICP-MS:

Comparison With Microwaveassisted Digestion-ICP-MS

Seven pharmaceutical ingredients were analyzed with the proposed method and by using a reference method with sample preparation by microwave-assisted digestion (MAD). The results are summarized in Table $\mathrm{V}$ and are in good agreement between the two methods. By applying a $t$-test (95\%), no statistical differences between the results were found. Finally, the levels found did not exceed the concentration limits for oral drug products (drug substances and excipients) established by USP Chapter $<232>$ and based on a typical maximum daily dosage of $\leq 10 \mathrm{~g} /$ day.

\section{CONCLUSION}

A method has been developed for the quality control of pharmaceutical ingredients based on the ultrasound-assisted extraction system for sample preparation and ICP-MS for the determination of nine elements (As, Cd, Cr, Cu, Ni, $\mathrm{Pb}, \mathrm{Pd}, \mathrm{Rh}$, and $\mathrm{V}$ ) recently proposed by the USP (9). UAE provides reproducible and accurate extraction of the analyzed elements from pharmaceutical samples and is able to accomplish the extraction of 30 samples in a total time of $30 \mathrm{~min}$ utes. Under these conditions, it is possible to state that the UAE method developed here is wellsuited for the routine analysis of numerous samples. The heterogeneous composition of the analyzed samples associated to the wide concentration ranges of the 9 targeted elements support the use of a widescope instrumental technique, namely ICP-MS. Moreover, the levels found for the ordinary samples did not exceed the concentration limits for oral drug products (drug substances and excipients) 
TABLE V

Results Obtained in the Analysis of 7 Active Pharmaceutical Ingredients by UAE-ICP-MS and MAD-ICP-MS, Expressed as the Mean Concentration ( $\mathrm{ng} \mathrm{g}^{-1}$ ) of Three Independent Samples \pm Standard Deviation (SD)

\begin{tabular}{lrllrrrrrr}
\hline Samples & Pd & Rh & Cd & \multicolumn{1}{c}{$\mathrm{Cu}$} & \multicolumn{1}{c}{$\mathrm{Pb}$} & \multicolumn{1}{c}{$\mathrm{Ni}$} & \multicolumn{1}{c}{ As } & \multicolumn{1}{c}{ Cr } & V \\
\hline Cephalexin (UAE) & $24 \pm 2$ & ND & ND & $101 \pm 3$ & $35 \pm 2$ & $69 \pm 3$ & ND & $107 \pm 3$ & ND \\
Cephalexin (MAD) & $27 \pm 1$ & ND & ND & $105 \pm 5$ & $42 \pm 2$ & $77 \pm 3$ & ND & $111 \pm 8$ & ND \\
Doxycycline (UAE) & $437 \pm 24$ & ND & ND & ND & ND & $39 \pm 1$ & $127 \pm 2$ & $705 \pm 20$ & ND \\
Doxycycline (MAD) & $430 \pm 14$ & ND & ND & ND & ND & $41 \pm 1$ & $128 \pm 5$ & $734 \pm 24$ & ND \\
Norfloxacin (UAE) & ND & ND & ND & ND & ND & $67 \pm 2$ & ND & ND & ND \\
Norfloxacin (MAD) & ND & ND & ND & ND & ND & $55 \pm 3$ & ND & ND & ND \\
Oxytetracycline (UAE) & ND & ND & ND & $130 \pm 5$ & ND & $769 \pm 33$ & ND & $374 \pm 17$ & $55 \pm 2$ \\
Oxytetracycline (MAD) & ND & ND & ND & $120 \pm 1$ & ND & $748 \pm 31$ & ND & $396 \pm 20$ & $62 \pm 3$ \\
P. G potassium (UAE) & $8.7 \pm 0.2$ & ND & ND & ND & ND & ND & ND & ND & ND \\
P. G potassium (MAD) & $8.1 \pm 1$ & ND & ND & ND & ND & ND & ND & ND & ND \\
Praziquantel (UAE) & ND & ND & ND & $31 \pm 1$ & ND & $44 \pm 1$ & ND & ND & ND \\
Praziquantel (MAD) & ND & ND & ND & $27 \pm 1$ & ND & $40 \pm 1$ & ND & ND & ND \\
Trimethoprim (UAE) & $6.7 \pm 0.3$ & ND & ND & ND & ND & ND & ND & $24 \pm 1$ & $17 \pm 1$ \\
Trimethoprim (MAD) & $6.1 \pm 0.5$ & ND & ND & ND & ND & ND & ND & $28 \pm 2$ & $12 \pm 2$ \\
\hline
\end{tabular}

UAE $=$ ultrasound-assisted extraction

$\mathrm{MAD}=$ microwave-assisted digestion .

$\mathrm{ND}=$ below the detection limit.

established by USP Chapter <232> and based on a typical maximum daily dosage of $\leq 10 \mathrm{~g} / \mathrm{day}$.

\section{ACKNOWLEDGMENT}

The authors are grateful to Fundação de Amparo à Pesquisa do Estado de São Paulo (FAPESP) and Conselho Nacional de Desenvolvimento Científico e Tecnológico (CNPq) for their support of this study.

$\overline{\text { Received February 5, } 2017 .}$

\section{REFERENCES}

1. ICH, Impurities in new drug substances Q3A (R2), in: International Conference on Harmonisation, IFPMA, Geneva, Switzerland (2006).

2. ICH, Impurities in new drug products Q3B (R2), in: International
Conference on Harmonisation, IFPMA, Geneva, Switzerland (2006).

3. ICH, Impurities Guideline for residual solvents Q3C (R5), in: International Conference on Harmonisation, IFPMA, Geneva, Switzerland (2011).

4. ICH, Impurities Guideline for metal impurities Q3D, in: International Conference on Harmonisation, IFPMA, Geneva (Switzerland) (2009).

5. S. Singh, T. Handa, M. Narayanam, A. Sahu, M. Junwal and R.P. Shah, J. Pharm. Biomed. Anal. 69, 148 (2012).

6. The United States Pharmacopoeia, The National Formulary, USP 35 NF30, <231> Heavy Metals. United States Pharmacopoeial Convention, 12601, Twinbrook Parkway, Rockville, MD 20852 USA (2012, p. 145)..

7. British Pharmacopoeia, 2008, The Stationery Office under license from The Controller of Her Majesty's Stationery Office, Norwich, England, A229, Limits test for heavy metals $(\mathrm{Ph}$. Eur. Meth. 2.4.8).

8. N. Lewen, S. Mathew, M. Schenkenberger and T. Raglione, J. Pharm. Biomed. Anal. 35, 739 (2004).

9. The United States Pharmacopoeia, Revision Bulletin - Official February, <233> Elemental Impurities Procedures. United States Pharmacopoeial Convention, 12601, Twinbrook Parkway, Rockville, MD 20852 USA (2013).

10. The United States Pharmacopoeia, Revision Bulletin - Official February, <232> Elemental Impurities Limits. United States Pharmacopoeial Convention, 12601, Twinbrook Parkway, Rockville, MD 20852 USA (2013).

11. C. Stoving, H. Jensen, B. Gammelgaard and S. Sturup, J. Pharm. Biomed. Anal. 84, 209 (2013). 


\section{Atomic $_{\text {Spectroscopy }}^{\text {to }}$ \\ 1 Vol. 38(6), Nov./Dec. 2017}

12. R.N. Rao and M.V.N.K. Talluri, J. Pharm. Biomed. Anal. 43, 1 (2007).

13. N. Lewen, J. Pharm. Biomed. Anal. 55, 653 (2011).

14. P.J. Parsons and F. Barbosa Jr, Spectrochim. Acta Part B 62, 992 (2007).

15. G. Doner and A. Ege, Anal. Chim. Acta 520, 217 (2004).

16. E.P. Nardi, F.S. Evangelista, L. Tormen, T.D. Saint 'Pierre, A.J. Curtius, S.S. de Souza and F. Barbosa Jr., Food Chem. 112, 727 (2009).

17. C.C. Nascentes, M. Korn and M.A.Z. Arruda, Microchem. J. 69, 37 (2001).

18. E.C. Lima, F. Barbosa Jr. and F.J. Krug, Anal. Chim. Acta 409, 267 (2000). 19. C.E.R. de Paula, L.F.S. Caldas, D.M. Brum and R.J. Cassella, J. Pharm. Biomed. Anal. 74, 284 (2013)

20. H. Sereshti, Y.E. Heravi and S. Samadi, Talanta 97, 235 (2012).

21. M.V. B. Krishna and J. Arunachalam, Anal. Chim. Acta 522, 179 (2004).

22. C. Venzago, M. Popp, J. Kovac and A. Kunkel, J. Anal. At. Spectrom. 28, 1125 (2013).

23. US Pharmacopeial Convention. Available at: http://www.usp.org/sites/default/f iles/usp_pdf/EN/USPNF/232_usp3 5s2.pdf (accessed on 05/22/2014)

24. S. D'Ilio, N. Violante, M. Di Gregorio, O. Senofonte and F. Petrucci, Anal. Chim. Acta 579, 202 (2006).

25. S. D'Ilio, N. Violante, S. Caimi, M. Di Gregorio, F. Petrucci and O. Senofonte, Anal. Chim. Acta 573, 432 (2006).

26. P. Heitland and K.D. Koster, Clin. Chim. Acta 365, 310 (2006).

27. S.D. Tanner, V.I. Baranov and D.R. Bandura, Spectrochim. Acta Part B 57, 1361 (2002)

28. D.E. Nixon, K.R. Neubauer, S.J. Eckdahl, J.A. Butz and M.F. Burritt, Spectrochim. Acta 59, 1377 (2004).

29. B. L. Batista, J. L. Rodrigues, J. A. Nunes, V. C. O. Souza and F. Barbosa Jr., Anal. Chim. Acta 639, 13 (2009).
30. B.L. Batista, J.L. Rodrigues, V.C.O. Souza and F. Barbosa Jr., Forensic Sci. Int. 192, 88 (2009).

31. D. Santos Jr, F. Barbosa Jr, S.S. Souza and F. J. Krug, J. Anal. Atom. Spectrom. 18, 939 (2003).

32. L. Fisher, B. Zipfel, G. Koellensper, J. Kovac, S. Bilz, A. Kunkel, C. Venzago and S. Hann, J. Pharm. Biom. Anal. 95, 121 (2014).

33. E.C. Lima, F. Barbosa Jr, F.J. Krug, M.M. Silva and M.G.R. Vale, J. Anal. Atom. Spectrom. 15, 995 (2000).

34. I. Lavilla, P. Vilas and C. Bendicho, Food Chem. 106, 403 (2008).

35. F.P. Capote and M.D. Luque de Castro, Anal. Bioanal. Chem. 387, 249 (2007) 